\title{
Death by Neurological Diseases Observed over Two Years in the Unit of Hospitalization of the Department of Neurology-Chu Cocody-Abidjan
}

\author{
Aka-Anghui Diarra Evelyne, Amon-Tanoh Muriel, Yapo-Ehounoud Constance, \\ Tanoh Christian, Ahuie Kouakou Fulbert \\ Departement of Nervous System and Rehabilitation, Université Félix Houphouët-Boigny, Abidjan, Ivory Coast \\ Email: evediarra@yahoo.fr, muriamon@gmail.com, aimeahuie@yahoo.f, \\ constanceyapoehounoud@gamail.com
}

Received 9 September 2015; accepted 24 September 2015; published 30 September 2015

Copyright (C) 2015 by authors and OALib.

This work is licensed under the Creative Commons Attribution International License (CC BY). http://creativecommons.org/licenses/by/4.0/

(c) (i) Open Access

\begin{abstract}
Introduction: The neurological diseases affect the central nervous system and peripheral. Our study was carried out in the unity of hospitalization of the department of neurology of the Hospital and university Center (CHU) of Cocody in Abidjan, economic capital of the Cote d'Ivoire, and concerned all the deaths to release the symptoms and the most lethal affections and the factors of bad forecast. The stroke remains burdened by a very high mortality in the world. Method of this study: It is about an analytical retrospective study which took place from January 1st, 2012 till December 31st, 2013. The results of this research were present, having the outcome of a thesis in medicine during the academic year 2014-2015. For the period of study, we included all the cases of the patients died during their stay and proceeded by drawing lots to a group witness. Results: During the period of study, the mortality was $\mathbf{2 1 . 8 \%}$. The most found stigmas of immunosuppression were: the loss of weight $(18.9 \%)$, the prurigo $(17 \%)$ and herpes zoster $(13.8 \%)$. The main neurological syndromes in the population of the dead subjects were: the pyramidal syndrome $(79.5 \%)$ and the meningeal irritation $(38.1 \%)$. The vascular pathologies $(43.9 \%)$ represented the first cause of death and interested especially the subjects the average age of which was of 62 years, followed by the infectious pathology $(30,5 \%)$ interesting especially the young adults. Numerous factors of bad forecasts, in particular clinical, biological, and medicinal, were significantly found. Conclusion and recommandations: The death by neurological disease has a not insignificant proportion. To prevent neurological diseases, prevention is the only effective measure, such as the prevention of neurological complications of hypertension and HIV-AIDS.
\end{abstract}

\section{Keywords}

Stroke, Mortality, Neurological Diseases

How to cite this paper: Evelyne, A.-A.D., Muriel, A.-T., Constance, Y.-E., Christian, T. and Fulbert, A.K. (2015) Death by Neurological Diseases Observed over Two Years in the Unit of Hospitalization of the Department of Neurology-Chu CocodyAbidjan. Open Access Library Journal, 2: e1907. http://dx.doi.org/10.4236/oalib.1101907 


\section{Introduction}

The neurological diseases affect the central nervous system and peripheral. They are mostly related to vascular etiologies and/or infectious. The stroke remains burdened by a very high mortality in the world. The nervous system constitutes a major target of several infectious complications directly HIV-related or in the opportunist affections. However, the aspect forecast with in particular the identification of the main factors driving to the deaths is not still perfectly clarified. The mortality constitutes a major indicator reflecting the level of socioeconomic development of a country and is the reflection of the quality of the care.

In our practice, insufficient diagnostics and lack appropriate technical facilities encourage high mortality due to neurological diseases. It thus seemed to us important to reveal the profile of the patients died from a neurological affection and to determine the factors of bad forecast and release the priorities of it with the aim of the improvement of the coverage.

\section{Materials and Methods}

All the cases of the patients admitted in hospitalization of neurology, died during their stay. We also included the third of all the not dead hospitalized patients drawn lots without purebred distinction, of nationality, sex and any socioeconomic conditions. The data collection is effectuee has to leave registers of hospitalization and cases of the patients hospitalize. The recorded data were analyzed by means of the software EPIDATA and the use of the test of $\mathrm{chi}^{2}$ or the test of the gap reduces.

\section{Results}

At the time of the admission, $80 \%$ of the subjects in the group of the dead did not know their serologique status for the HIV, against $84.8 \%$ in the population of the not dead subjects. The difference was not significant $(\mathbf{p}=$ 0.2). The opportunist infections, the stigmas of immunosuppression are listed on the Figure 1 . In the admission, the main motives for hospitalization were the disordersof the consciousness $64.7 \%$, the driving deficits $40.4 \%$ and the headaches 29.2\% (Figure 2). In the neurological examination the pyramidal achievements were dominating. Other syndromes and found signs are listed in Table 1. The cytological analysis of the CSF was

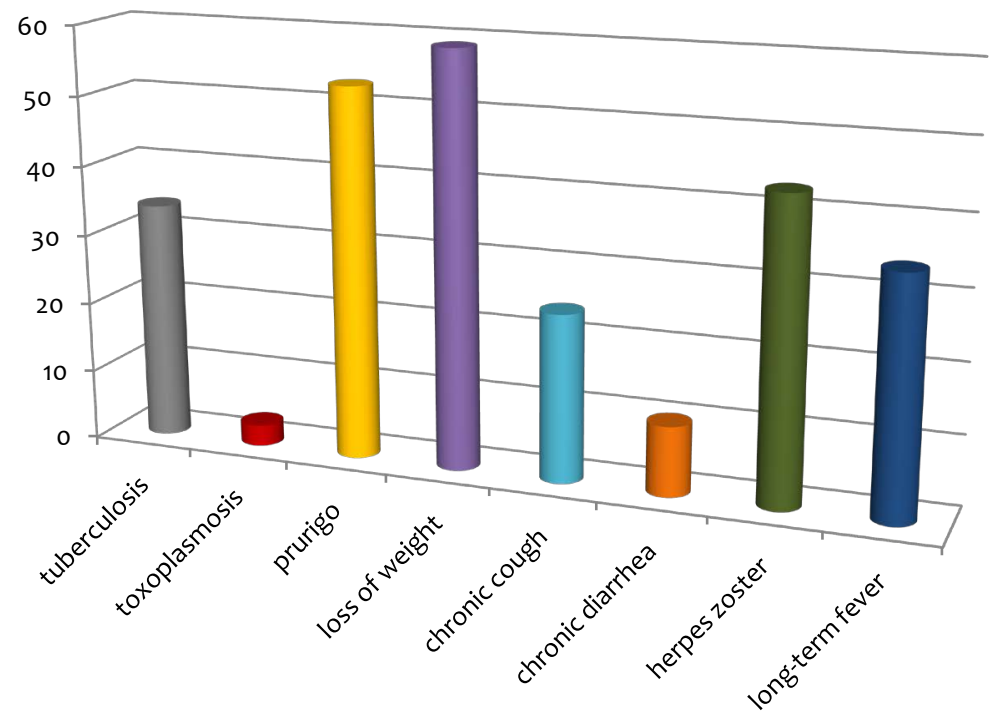

Figure 1. Distribution of the opportunist affections in the group of the dead subjects. 


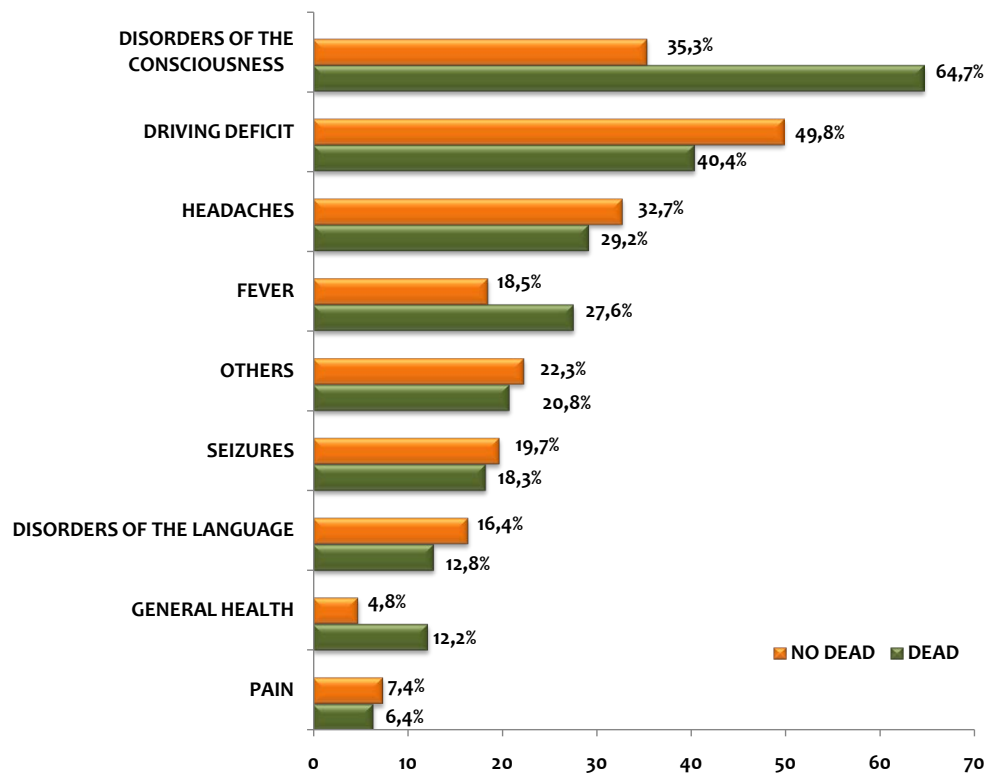

Figure 2. Distribution of the population of study according to the motive for consultation.

Table 1. Distribution of the population of study according to the syndromes or the clinical signs.

\begin{tabular}{|c|c|c|c|c|c|c|}
\hline The syndromes & Dead & $\%$ & No dead & $\%$ & Total & $\mathbf{P}$ \\
\hline Meningeal irritation & 119 & 38.1 & 53 & 19.7 & 172 & $0.00(\mathrm{~s})$ \\
\hline Syndrome of medullary compression & 13 & 4.2 & 19 & 7.1 & 32 & 0.13 (ns) \\
\hline Pyramidal syndrome & 248 & 79.5 & 201 & 74.7 & 449 & 0.17 (ns) \\
\hline Extrapyramidal syndrome & 2 & 0.6 & 3 & 1.1 & 5 & $0.53(\mathrm{~ns})$ \\
\hline Syndrome peripheral neurogene & 13 & 4.2 & 10 & 3.7 & 23 & 0.95 (ns) \\
\hline Encephalic syndrome & 48 & 15.4 & 21 & 7.8 & 69 & $0.00(\mathrm{~s})$ \\
\hline Sensory syndrome & 16 & 5.1 & 50 & 18.6 & 66 & $0.00(\mathrm{~s})$ \\
\hline Comitial syndrome & 50 & 16 & 44 & & 94 & 0.98 (ns) \\
\hline Achievement of cranial nerves & 29 & 9.3 & 19 & 7.1 & 48 & $0.00(\mathrm{~s})$ \\
\hline Anomaly of the superior functions & 20 & 6.4 & 25 & 9.4 & 45 & $0.00(\mathrm{~s})$ \\
\hline Disorders trophiques & 37 & 11.9 & 21 & 7.8 & 58 & 0.15 (ns) \\
\hline Disorder sphincter & 60 & 19.2 & 45 & 16.7 & 105 & 0.23 (ns) \\
\hline Coma & 27 & 8.7 & 8 & 3 & 35 & 0.00 (ns) \\
\hline $\begin{array}{c}\text { Syndrome of intra-cranial high blood } \\
\text { pressure }\end{array}$ & 27 & 8.7 & 20 & 7.5 & 47 & 0.59 (ns) \\
\hline Confusionnel syndrome & 25 & 8 & 18 & 6.7 & 43 & 0.54 (ns) \\
\hline
\end{tabular}

in favour of a biological meningitis in the group of the subjects died (Table 2). The vascular pathologies represented the first cause of deaths (43.9\%) with the mean age was of 62 years (Table 3). The main complication in the course of hospitalization in the group of the dead subjects was a bedsore $\mathbf{3 8 . 8} \%$ (Figure 3 ). The mortality rate was $\mathbf{2 1 . 8} \%$.

\section{Discussion}

The presence of disorders of the consciousness, of a driving deficit are according to our study are pejorative 


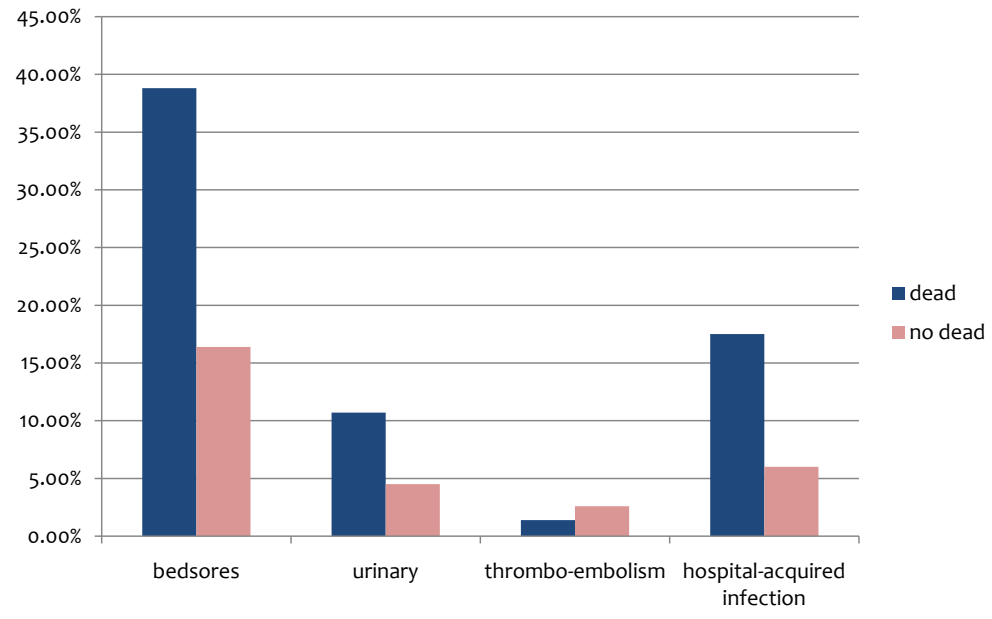

Figure 3. Distribution of deaths according to the complications of decubitus outstanding discounted bills of hospitalization.

Table 2. Distribution of population of study according to the aspect of CSF.

\begin{tabular}{cccccccccc}
\hline Aspect of CSF & \multicolumn{3}{c}{ Cytology } & \multicolumn{2}{c}{ Proteinorachie } & \multicolumn{3}{c}{ Glucorachie } \\
\hline & $<5$ elements & $\mathbf{2}$ elements & {$[0-0,4]$} & {$[1-22]$} & $\mathbf{> 2 2}$ & no reached & {$[0-0,4]$} & {$[0,5-1]$} & $>\mathbf{1}$ \\
\hline \multirow{2}{*}{ non dead } & 35 & 29 & 2 & 11 & 49 & 2 & 17 & 31 & 10 \\
dead & 19 & $\mathbf{4 0}$ & 0 & 10 & $\mathbf{4 6}$ & 3 & 20 & 18 & $\mathbf{2 1}$ \\
\hline
\end{tabular}

Table 3. Distribution of the deaths by age bracket according to both pathologies suppliers of mortality.

\begin{tabular}{|c|c|c|c|c|}
\hline \multirow[b]{2}{*}{ Age (years) } & \multicolumn{4}{|c|}{ Etiologies } \\
\hline & Vascular $(\mathbf{n}=\mathbf{1 3 7})$ & $\%$ & Infectious ( $\mathbf{n}=\mathbf{9 5}$ ) & $\%$ \\
\hline $0-15$ & 1 & 0.7 & 0 & 0.0 \\
\hline $16-19$ & 0 & 0.0 & 3 & 3.2 \\
\hline $20-35$ & 4 & 2.9 & 29 & 30.5 \\
\hline $36-55$ & 36 & 26.3 & 43 & 45.3 \\
\hline $56-65$ & 35 & 25.5 & 16 & 16.8 \\
\hline $66-99$ & 61 & 44.5 & 4 & 4.2 \\
\hline Total & 137 & 100 & 95 & 100 \\
\hline Average age & \multicolumn{2}{|l|}{62} & \multicolumn{2}{|c|}{43.3} \\
\hline $\mathrm{P}$ & \multicolumn{2}{|l|}{0.06} & \multicolumn{2}{|c|}{0.00} \\
\hline
\end{tabular}

symptoms. They have to impose a particular supervision, an early etiological investigation. Besides the symptoms of immunosuppression are significantly correlated to the deaths. The presence of these signs has to arouse a screening of the HIV and the adequate precautionary and curative measures. In practice financial difficulties, insufficiency or absence of certain reactives, unavailability of laboratories are so much report which hinders certain urgent practices. However when analyses are possible the results in favour of meningitises with hypercytorachie, hypoglycorachie and hyperprotéinorachie are elements of bad forecasts.

The intellectual scanning (CT-scan) remains the examination of inescapableimaging in our practice with a rate of $87 \%$ realization in our series, $97.5 \%$ in the study of Aka Diarra et al. [1]. It contributes to the precision of the various types of brain damages and to their topographic localization. This rate is probably underestimated 
considering the unimplemented CT-scanbecause of the cost and the early deaths. In the various studies carried out in our department, Kourouma finds the ascendancy of the vascular pathologies [1], as in our study with 43.9\% of the cases followed by the infectious pathologies $30.5 \%$. It seems in our study that it is the elderly who die most pathologies of vascular origin, while the young subjects die rather from neurological affections of infectious origin. It was about a little surprising observation there because we know that the age is a vascular risk factor.

These percentages join those of AVODE who noted a mean age of 57.67 ans [2] for the stroke and a mean age of 39 years for the infectious pathology. Frédérike et al. who calculateon average a year $8 \%$ of deaths of vascular étiologiesarisen before the age of 65 years [3]. In west the global mortality connected to the vascular pathology is $22.9 \%$ with an average age of arisen the higher stroke [4]. The people die prematurely from vascular pathology in developing countries. The fragility of the social network, the inaccessibility in the system of care may explain partially this observed disparity. Bedsores are significantly more present in the group of dead patients. This factor of bad forecast questions the good practice of the measures of nursing because of the shortage of qualified staff or the absence of anti mattress bedsores. These complications, following the example of the pathology under ownerless, contribute to a percentage of almost constant death. The presence of stigmas of immunosuppression in the HIV, a meningitis lymphocytaire with hypoglycorachie and hyperproteinorachie, the use of measures of resuscitation and the arisen of complications of decubitus constitute the most important risk factors of mortality.

\section{Conclusion}

The various epidemiological, clinical and paraclinical parameters were correlated in the mortality to take out again the factors of bad forecast. Our study highlighted: the profile of the dead patients, two major pathologies suppliers of death and the factors of bad forecast require the mobilization of all the skills with the aim of the prevention and the ideal coverage of the patients to reduce the rate of deathby neurological diseases. So, you can make sensitive for an alive screening and a care of the people HIV-AIDS, complications of hypertension and strengthening of the hospitable equipements. Furthermore, the hospital hygiene precautions should be conducted regularly and on a daily basis to avoid the complications of decubitus. At the place of health authorities, they must make effective health care for all by the effective functioning of health coverage.

\section{References}

[1] Aka-Anghui Diarra, E., Kourouma, M. and Tanoh, C. (2015) Distribution of the Neurological Affections: Experience of the Department of Neurology of the Fallen of Cocody. Available in the Newspaper of Neurology Neurosurgery Psychiatry Flight: 1, in January.

[2] Avode, D.G., Adjien, C., Houinato, D., Souinhin, M. and Adoukonou, T. (2005) Toxoplasmosis Cerebral in a Hospital Environment in Cotonou (BENIN). African Journal of Neurological Sciences, 24, 48-54. http://ajns.paans.org/dist/data/2005Vol24No2.pdf

[3] Neau, J.-P., Faranpour, F., Alberque, C., Vivier-Darrigol, C., Durandet, G.J. and Frederike, L. (2012) The Cerebrovascular Accident in Poitou-Charentes. Bulletin d'observation santé. Poitou-Charentes. Accident Vasculaire Cerebral/ October 2012.

http://www.ars.poitou-charentes.sante.fr/fileadmin/POITOU-CHARENTES/Votre Sante/Maladies chroniques/201210 AVC-PCh-BOS-ORS.pdf

[4] Feigin, V.L., Lawes, C.M., Bennett, D.A. and Anderson, C.S. (2003) Stroke Epidemiology: A Review of PopulationBased Studies of Incidence, Prevalence, and Case-Fatality in the Late 20th Century. The Lancet Neurology, 2, 43-53. http://dx.doi.org/10.1016/S1474-4422(03)00266-7

\section{List of Abreviations}

CSF: cerebrospinal fluid

AIDS: acquired immunodeficiency syndrome

HIV: human immunodeficiency virus

CHU: Hospital and university Center

EPIDATA: EAR dated

CT-scan: Scanning 